\title{
Thermal Detection of Glucose in Urine using a Molecularly Imprinted Polymer as Recognition Element.
}

\section{Supplementary information}

Manlio Caldara ${ }^{1 *}$, Joseph W. Lowdon', Renato Rogosic ${ }^{1}$, Rocio Arreguin-Campos ${ }^{1}$, Kathia L. Jimenez-Monroy', Benjamin Heidtt, Kristina Tschulik², Thomas J. Cleij ${ }^{1}$, Hanne Diliën', Kasper Eersels ${ }^{1}$ and Bart van Grinsven ${ }^{1}$

1. Sensor Engineering Department, Faculty of Science and Engineering, Maastricht University, P.O. Box 616, 6200 MD Maastricht, the Netherlands

2. Faculty of Chemistry and Biochemistry, Analytical Chemistry II, Ruhr University Bochum, Universitätsstr. 150, ZEMOS, 44801 Bochum, Germany

*Corresponding author: m.caldara@maastrichtuniversity.nl

\section{Supplementary: Figures}

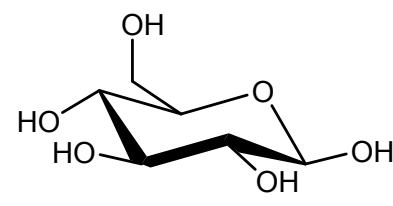

Glucose

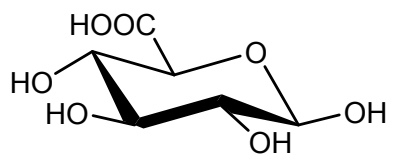

Glucuronic acid

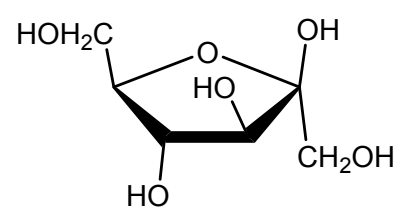

Fructose<smiles>OC[C@H]1O[C@H](O)[C@H](O)[C@@H](O)[C@@H]1O[C@H]1O[C@H](CO)[C@H](O)[C@H](O)[C@H]1O</smiles>

Lactose<smiles>OC[C@H]1O[C@](CO)(O[C@H]2O[C@H](CO)[C@H](O)[C@@H]2O)[C@H](O)[C@@H]1O</smiles>

Sucrose

Figure S1. Chemical structures of Glucose, Glucuronic acid, Fructose, Lactose and Sucrose. 

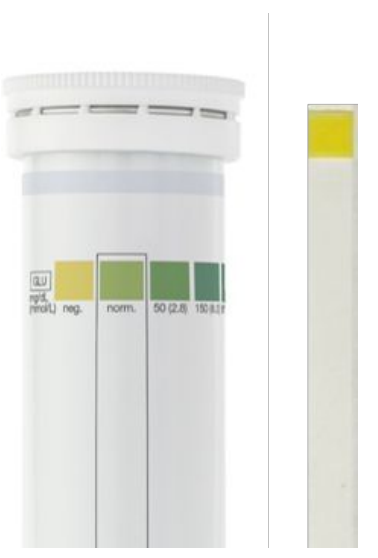

Figure S2. Test strips for detection of glucose in urine show no presence of glucose in the collected urine samples. 